\title{
AN ANALYTICAL STUDY TO EVALUATE SEVERITY OF DIABETIC RETINOPATHY AND INCIDENCE OF NEUROPATHY, NEPHROPATHY IN PATIENTS WITH TYPE 2 DIABETES MELLITUS
}

Karupputhevar Senthil1, Pandiaraj Saravanasankar², Mohan Bagavathshalini3, Madhavan Hemmanthraj ${ }^{4}$, Rethy Sreekumar Sruthi ${ }^{5}$, Francis Xavier Rajan Cinushamasilthilakraj6, Abdullah Haroon Shaminabegum ${ }^{7}$

1 Professor, Department of Diabetology, Madurai Medical College.

${ }^{2}$ Assistant Professor, Department of Ophthalmology, Madurai Medical College.

${ }^{3}$ Senior Resident, Department of Ophthalmology, Madurai Medical College.

${ }^{4}$ Junior Resident, Department of Ophthalmology, Madurai Medical College.

5Junior Resident, Department of Ophthalmology, Madurai Medical College.

6Junior Resident, Department of Ophthalmology, Madurai Medical College.

7Junior Resident, Department of Ophthalmology, Madurai Medical College.

ABSTRACT

\section{BACKGROUND}

Diabetes mellitus is one of the major health problems that have a significant impact on the socioeconomic life of the individual. According to the International Diabetes Federation, 381 million people worldwide suffer due to diabetes. In India, 62 million suffer from diabetes and 1 million die every year due to diabetes. Diabetic patients, during the course of disease, develop microvascular and macrovascular complications. Glycaemic control is of utmost importance in the preventing death due to microvascular and macrovascular complications.

The aim of our present study is to analyse the diabetic complications - nephropathy and neuropathy depending on the severity of retinopathy in type 2 diabetic patients.

\section{MATERIALS AND METHODS}

An analytical study conducted among 100 type 2 DM patients who attended the outpatient department and as inpatients admitted to the wards of the Department of Ophthalmology, Government Rajaji Hospital, Madurai, and who satisfied the eligibility criteria for over a period of 5 months. Assessment of diabetic retinopathy was done as per Early Treatment of Diabetic Retinopathy Study (ETDRS) classification. Diabetic Nephropathy was assessed by albuminuria, serum creatinine and blood urea. Diabetic Neuropathy was assessed by Neuropathy Disability Score which includes Vibration perception test, Temperature perception test, Pinprick test, Ankle jerk. Analysis of nephropathy and neuropathy was done depending on severity of Retinopathy in type 2 diabetic patients.

Observation-Patients with mild NPDR showed 100\% subclinical albuminuria, patients with moderate NPDR showed 97.6\% microalbuminuria and $2.4 \%$ showed macroalbuminuria and in those patients with severe NPDR, very severe NPDR, early PDR, highrisk PDR and diabetic maculopathy, showed 100\% macroalbuminuria. Lower limb assessment for diabetic neuropathy, showed neuropathy in $29 \%$ cases.

\section{RESULTS}

Diabetic retinopathy has a significant association with blood urea and serum creatinine with significant 'p' value of 0.0001 . Neuropathy was $100 \%$ absent in mild and moderate NPDR and 100\% present in severe NPDR, very severe NPDR, early PDR, highrisk PDR and diabetic maculopathy.

\section{CONCLUSION}

Among patients presented in our study, the severity of diabetic retinopathy correlates well with significant incidence and severity of nephropathy and peripheral neuropathy.

\section{KEYWORDS}

Diabetes Mellitus Complications, Diabetic Nephropathy, Diabetic Neuropathy.

HOW TO CITE THIS ARTICLE: Senthil K, Saravanasankar P, Bagavathshalini M, et al. An analytical study to evaluate severity of diabetic retinopathy and incidence of neuropathy, nephropathy in patients with type 2 diabetes mellitus. J. Evolution Med. Dent. Sci. 2016;5(93):6875-6878, DOI: 10. 14260/jemds/2016/1554

Financial or Other, Competing Interest: None.

Submission 12-10-2016, Peer Review 10-11-2016,

Acceptance 16-11-2016, Published 21-11-2016.

Corresponding Author:

Dr. Karupputhevar Senthil,

\# 7/478, Theni Road,

Checkanurani,

Madurai-625514, Tamilnadu.

E-mail: doctorksenthil@gmail.com

DOI: 10. 14260/jemds/2016/1554

\section{BACKGROUND}

Diabetes mellitus (DM) is a metabolic disorder with a disturbance in carbohydrate, protein, and fat metabolism because of partial or complete deficiency of insulin secretion or its action. DM is one of the major health problems that have a significant impact on the socioeconomic life of the individual. According to the International Diabetes Federation, 381 million people worldwide suffer due to diabetes. In India, 62 million suffer from diabetes and 1 million die every year ${ }^{1}$ due to diabetic complications. 
Diabetic patients during the course of disease develop microvascular and macrovascular complications. Glycaemic control is of utmost importance in preventing death due to microvascular and macrovascular complications. ${ }^{2}$ The aim of our present study is to analyse the diabetic complications presence of nephropathy and or neuropathy depending on the severity of retinopathy in type 2 diabetic patients.

\section{MATERIALS AND METHODS}

An analytical study conducted among 100 type 2 DM patients who attended the outpatient department and inpatients admitted in the wards of the Department of Ophthalmology, Government Rajaji Hospital, Madurai, and who satisfied the eligibility criteria for over a period of 5 months. Inclusion criteria were: Patients diagnosed with type 2 diabetes, on treatment; duration of diabetes $>5$ years and age of the patient $\geq 40$ years. Exclusion criteria were patients with known history of thyroid disorder, pregnant women, patients in whom fundus cannot be examined, glaucoma patients, patients who had undergone laser photocoagulation, patients on dialysis, patients on treatment for hypertension and patients not consenting for the study. Assessment of diabetic retinopathy was done as per Early Treatment of Diabetic Retinopathy Study (ETDRS) ${ }^{3}$ classification. Diabetic Nephropathy was assessed by albuminuria, serum creatinine and blood urea levels. Diabetic Neuropathy was assessed by Neuropathy Disability Score 4 which includes Vibration perception test, Temperature perception test, Pinprick test, Ankle jerk. Analysis of Nephropathy and Neuropathy depending and severity of Retinopathy in Type 2 diabetic patients was done using Epidemiological Information Package (EPI 2010) developed by Centre for Disease Control, Atlanta and ' $p$ '- value less than 0.05 is taken to denote significant relationship.

\section{OBSERVATION AND RESULTS}

The average age group of patients presenting with diabetic retinopathy in our study was 50-70 years, among them 55\% were male and $45 \%$ were female, showing male preponderance. Patients with diabetes for $>5$ years showed some stage of diabetic retinopathy; $34 \%$ with mild NPDR, $41 \%$ moderate NPDR, $8 \%$ severe NPDR, $75 \%$ very severe NPDR, $4 \%$ early PDR, 3\% high risk PDR, 3\% diabetic maculopathy (Fig: 1) with the mean duration as 8 years. Visual acuity was normal $6 / 6$ in 41 eyes, $6 / 6$ p to $6 / 12$ in 98 eyes and $6 / 18$ to $6 / 60$ in 61 eyes. The defective vision in these patients were due to lens changes, posterior capsular opacification following cataract surgery with Posterior Chamber Intraocular Lens (PCIOL) implantation and diabetic retinopathy. On the assessment of renal function for diabetic nephropathy; $66 \%$ of patients showed abnormally elevated blood urea level, $70 \%$ patients had abnormally elevated serum creatinine level, $41 \%$ patients showed microalbuminuria and $25 \%$ patients showed macroalbuminuria. Patients with mild NPDR showed 100\% subclinical albuminuria, patients with moderate NPDR showed $97.6 \%$ microalbuminuria and $2.4 \%$ showed macroalbuminuria and in those patients with severe NPDR, very severe NPDR, early PDR, high-risk PDR and diabetic maculopathy, showed $100 \%$ macroalbuminuria (Table 1). On the assessment of right and left leg for diabetic neuropathy, $29 \%$ showed neuropathy. Neuropathy was $100 \%$ absent in mild and moderate NPDR and 100\% present in severe NPDR, very severe NPDR, early PDR, high-risk PDR and diabetic maculopathy (Table 2).

Study patients with various stages of diabetic retinopathy were divided into two groups: Group 1 includes mild and moderate NPDR and Group 2 includes severe NPDR, very severe NPDR, early PDR, high-risk PDR and diabetic maculopathy. The available data in the two groups showed a statistically significant correlation between severity of retinopathy with incidence of nephropathy and retinopathy with incidence of neuropathy with a ' $\mathrm{p}$ '- value, $\mathrm{p}$ less than 0.0001 (Table 3).

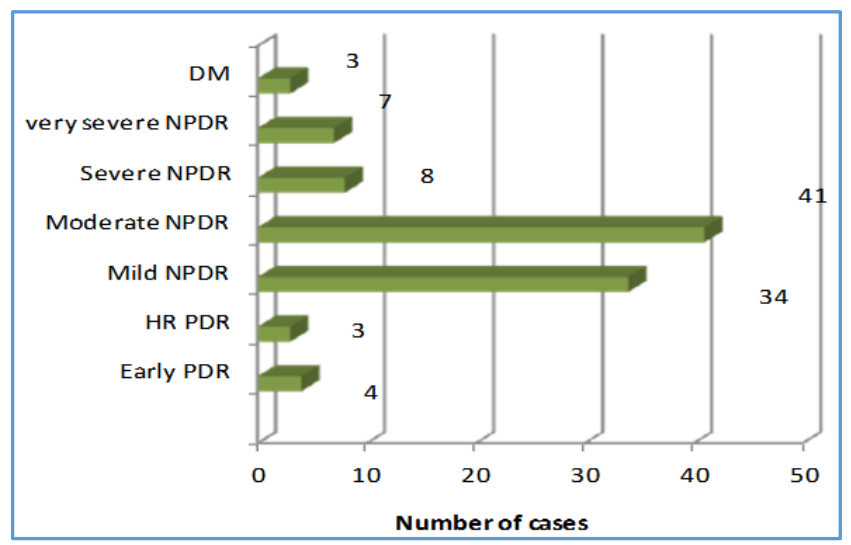

Figure 1. Graph showing the Stage of Retinopathy in our Study Subjects

\begin{tabular}{|c|c|c|c|c|c|c|c|}
\hline \multirow{2}{*}{$\begin{array}{c}\text { Stage of } \\
\text { Retinopathy }\end{array}$} & \multirow{2}{*}{$\begin{array}{c}\text { No. of Study } \\
\text { Patients with } \\
\text { Retinopathy }\end{array}$} & \multicolumn{3}{|c|}{$\begin{array}{c}\text { Normo } \\
\text { Albuminuria }\end{array}$} & \multicolumn{2}{c|}{$\begin{array}{c}\text { Micro } \\
\text { Albuminuria }\end{array}$} & \multicolumn{2}{c|}{$\begin{array}{c}\text { Macro } \\
\text { Albuminuria }\end{array}$} \\
\cline { 3 - 8 } & & No. & \% & No. & \% & No. & \% \\
\cline { 3 - 8 } & & 34 & 100 & - & - & - & - \\
\hline Mild NPDR & 41 & - & - & 40 & 97.6 & 1 & 2.4 \\
\hline Moderate NPDR & 8 & - & - & - & - & 8 & 100 \\
\hline Severe NPDR & 7 & - & - & - & - & 7 & 100 \\
\hline Very severe NPDR & 4 & - & - & - & - & 4 & 100 \\
\hline Early PDR & 3 & - & - & - & - & 3 & 100 \\
\hline HR PDR & 3 & - & - & 1 & 33.3 & 2 & 66.7 \\
\hline DM & \multicolumn{2}{|c|}{ Table 1. Showing the Presence of Retinopathy and Nephropathy } \\
\hline
\end{tabular}




\begin{tabular}{|c|c|c|c|c|c|}
\hline \multirow{3}{*}{ Stage of Retinopathy } & \multirow{3}{*}{$\begin{array}{l}\text { No. of Study Patients } \\
\text { with Retinopathy }\end{array}$} & \multicolumn{4}{|c|}{ Neuropathy } \\
\hline & & \multicolumn{2}{|c|}{ Present } & \multicolumn{2}{|c|}{ Absent } \\
\hline & & No. & $\%$ & No. & $\%$ \\
\hline Mild NPDR & 34 & - & - & 34 & 100 \\
\hline Moderate NPDR & 41 & - & - & 41 & 100 \\
\hline Severe NPDR & 8 & 8 & 100 & - & - \\
\hline Very severe NPDR & 7 & 7 & 100 & - & - \\
\hline Early PDR & 4 & 4 & 100 & - & - \\
\hline HR PDR & 3 & 3 & 100 & - & - \\
\hline DM & 3 & 3 & 100 & - & - \\
\hline
\end{tabular}

\begin{tabular}{|c|c|c|c|c|c|}
\hline \multirow{2}{*}{ Retinopathy } & \multirow{2}{*}{$\begin{array}{c}\text { No. of Study } \\
\text { Patients }\end{array}$} & $\begin{array}{c}\text { No. of Patients with } \\
\text { Normoalbuminuria }\end{array}$ & $\begin{array}{c}\text { No. of Patients } \\
\text { with } \\
\text { Microalbuminuria }\end{array}$ & $\begin{array}{c}\text { No. of Patients } \\
\text { with } \\
\text { Macroalbuminuria }\end{array}$ & $\begin{array}{c}\text { No. of Patients } \\
\text { with Neuropathy }\end{array}$ \\
\hline Group 1 & 75 & 34 & 40 & 1 & 0 \\
\hline Group 2 & 25 & - & 1 & 24 & 100 \\
\hline 'P' value & \multicolumn{7}{|c|}{ Table 3. Showing the Statistical Analysis between Group 1 and Group 2 } \\
of Diabetic Retinopathy, Nephropathy and Neuropathy
\end{tabular}

\section{DISCUSSION}

It is known that diabetes mellitus result in microvascular and macrovascular complications. The microvascular disease tends to occur predominantly in vascular endothelium of kidney, retina and vasa nervorum where glucose uptake is independent of insulin activity. The underlying driver of microvascular disease is tissue exposure to chronic hyperglycaemia ${ }^{5}$ and relationship between microvascular disease and glucose control is established by United Kingdom Prospective Diabetes Study ${ }^{6}$ (UKPDS) and Diabetes Control of Complications Trial7 (DCCT). The pathophysiological process occurring in vessels of the retina, peripheral nerve and kidney are very similar, results in increased basement membrane thickening, loss of pericytes and smooth muscle cells of retinal vessels, microaneurysm formation and mesangial nodule formation in kidney and endothelial hyperplasia in vasa nervorum. There are two aspects of vascular damage ${ }^{8}$ in microvascular complications namely underperfusion and overperfusion that leads to retinal haemorrhages and epineural haemorrhage seen in nerve biopsies. These common pathways lead to damage in target organ namely retina, peripheral nerves and kidneys in our study. Study by Valensi et al showed the correlation of presence of clinical neuropathy with presence of retinopathy, arterial hypertension, macroangiopathy, and biological signs of nephropathy. All the electrophysiological parameters were significantly more abnormal in patients with retinopathy. ${ }^{9} \mathrm{~A}$ prospective case control study conducted at Aravind Eye Hospital in 2001 showed that macular ischaemia is an important marker for nephropathy in type $2 \mathrm{DM}$ which was explained by ischaemic microangiopathy in both end organs of retina and kidney. ${ }^{10}$ This study showed a significant correlation between severity of retinopathy and severity of neuropathy and/or nephropathy.

\section{CONCLUSION}

Among patients presented in our study, the severity of diabetic retinopathy correlates well with significant incidence and severity of nephropathy and peripheral neuropathy. Patients diagnosed with diabetic retinopathy of any stage should be referred to diagnose neuropathy and nephropathy to prevent life-threatening complications.

\section{REFERENCES}

1. Wild S, Roglic G, Green A, et al. Global prevalence of diabetes: estimates for the year 2000 and projections for 2030. Diabetes Care 2004;27(5):1047-53.

2. Moore DJ, Gregory JM, Kumah-Crystal YA, et al. Mitigating micro and macro-vascular complications of diabetes beginning in adolescence. Vasc Health Risk Manag 2009;5:1015-31.

3. Venkatesh P, Sharma R, Vashist N, et al. Detection of retinal lesions in diabetic retinopathy: comparative evaluation of 7-field digital color photography versus redfree photography. Int Ophthalmol 2015;35(5):635-40.

4. Weintrob N, Amitay I, Lilos P, et al. Bedside neuropathy disability score compared to quantitative sensory testing for measurement of diabetic neuropathy in children, adolescents and young adults with type 1 diabetes. J Diabetes Complications 2007;21(1):13-9.

5. Kawahito S, Kitahata H, Oshita S. Problems associated with glucose toxicity: role of hyperglycemia-induced oxidative stress. World J Gastroenterol 2009;15(33):4137-42.

6. UK Prospective Diabetes Study (UKPDS) Group. Intensive blood glucose control with sulphonylureas or insulin compared with conventional treatment and risk of complications with type 2 diabetes. (UKPDS 33). Lancet 1998;352(9131):837-53.

7. Diabetes Control and Complications Trial Research Group. The effect of intensive treatment of diabetes on the development and progression of long term complications in adolescents insulin dependent diabetes mellitus. N Eng J Med 1993;329:977-86. 
8. Chiu JJ, Chien S. Effects of disturbed flow on vascular endothelium: pathophysiological basis and clinical perspectives. Physiol Rev 2011;91(1):327-87.

9. Valensi P, Giroux C, Seeboth-Ghalayini B, et al. Diabetic peripheral neuropathy: effects of age, duration of diabetes, glycemic control and vascular factors. J Diabetes Complications 1997;11(1):27-34.
10. Shukla D, Kolluru CM, Singh J, et al. Macular ischaemia as a marker for nephropathy in diabetic retinopathy. Indian J Ophthalmol 2004;52(3):205-10. 